but even though scholars might nitpick on the specifics, the overall picture he creates is argued convincingly.

Fagan concludes the book with a brief review of the evidence that recent years have seen accelerated warming. "With the Industrial Revolution, we took a great stride into an era in which we are frighteningly exposed to potential cataclysm, enhanced by our own seeming ability to warm the earth and increase the probability of extreme climatic events." What lesson has he gleaned from his

\section{Together forever?}

\section{One of Us: Conjoined Twins and} the Future of Normal

by Alice Dormurat Dreger

Harvard University Press: 2004. 224 pp.

$\$ 22.95, £ 14.95$

\section{Jonathan Cole}

Chang and Eng Bunker, the original (and self-styled) Siamese twins, travelled widely, married and had 22 children between them. As far as we know, they seemed happy with their conjoined state and only contemplated separation, late in their lives, to please their wives. A pair of American conjoined twins, Abigail and Brittany Hensel, who share one body, have required little medical care and live happily, enjoying swimming and cycling. And Yvonne and Yvette McCarther did not regard themselves as handicapped or deformed but merely different.

In One of Us, medical historian Alice Dormurat Dreger uses the personal accounts of such twins, and those of their parents and medical carers, to invite us to see conjoined twins as they see themselves. Many enjoy well-adjusted, rich lives, made possible by the development of cooperation strategies; these often work so well that Dreger suggests we could all learn from them. They find ways of becoming individuals, with different interests, while retaining a deep bond with their twin. As Lori Schappell says, "I'm a conjoined twin...but I do not live a conjoined life. The only time I think of it is when I'm interviewed. It's just an integral part of my life." Dreger suggests that although being conjoined is not preferable to being a singleton, conjoined twins generally accept it as part of their identity. The Iranian conjoined twins Ladan and Laleh Bijani were apparently the first in history to ask for a separation; most seem not to have contemplated it.

The types of conjoining vary, from the Bunkers' sharing of some abdominal organs to the joining of heads or pelvises. These differences are crucial when separation is contemplated. Dreger discusses whether surgery is done for medical reasons or for psychosocial reasons, to 'normalize' appearance. She admits that life can be easier for a singleton historical review? "Like many civilizations before us, we've simply traded up in scale, accepting vulnerability to the big, rare disaster in exchange for a better ability to handle the smaller, more common stresses such as short-term droughts and exceptionally rainy years." He worries that, terrible as the death tolls have been in recent years from famines and natural disasters, the potential demographic tragedies from the inevitable climatic swings of the future could be simply horrific - especially as governments around the world do not seem to be paying enough attention to this probability.

Whether or not one agrees with Fagan's conclusions, his arguments are clearly drawn and deserve careful scrutiny. The LongSummer is a compelling and fascinating book that should interest a broad scholarly audience and general readers alike.

Jeremy A. Sabloff is at the University of Pennsylvania Museum of Archaeology and Anthropology, 3260 South Street, Philadelphia, Pennsylvania 19104-6324, USA. than a conjoined person, but suggests that many conjoined twins accept and even prefer being conjoined, although there is evidence that some conjoined twins have been grateful for separation. They may also be more vulnerable, as such operations are typically performed in childhood, before their consent can be obtained. Generalization is difficult, however, not least because, like the rest of us, conjoined twins may have differing opinions.

Dreger deconstructs some of the more recent separations. Although rare, these cases have attracted huge publicity as they move from the personal and medical to the ethical, religious, social and legal. Balancing long-term survival of one or both conjoined twins with their associated morbidity must be extraordinarily difficult. In discussing these high-profile cases, Dreger draws out the presumption that she finds underlying most singletons' opinions, whether medical or legal, that life as a conjoined twin is somehow less desirable. She asks us to compare saving one conjoined twin by accelerating the death of the other with asking one of two singleton twins to make a similar sacrifice.

In this, and throughout the book, runs the thread implicit in her subtitle, "the future of normal". She questions whether difference has to be viewed as an impairment and whether impairment is tragic. The mother of conjoined twins is quoted as saying that "the only tragedy is in their interpretation of the girls' situation, since Ruthie and Verena are happy kids". Disability arises not from the impairment but from the response to it in those around, and so is socially induced; it is "about a failure to build ramps [rather] than legs that don't move”.

One consequence of viewing difference as an impairment is the pressure for medical intervention and normalization. The arguments that Dreger gives against these arose when the disabled borrowed from other rights movements to challenge restrictions imposed by difference, whether in anatomy, employment or gender orientation. Why, Dreger asks, "should people with unusual anatomies be treated as if their socially challenging bodies are inherently diseased?" Rather than guaranteeing a child a 'normal' body, we can "try to guarantee a just world".

These are huge questions, not least in considering the situation of any individual with impairment in the world as it is now, which guide the approach of medical workers. To those coming to these arguments afresh, they may prove quite a stretch. Dreger makes no claim to know all the answers but, by taking their side so eloquently, she invites us to see conjoined twins as "no more broken than the rest of us". This book is an eloquent and humane plea to see conjoined twins, and others with impairment and disability, as 'us' and not 'them'.

Jonathan Cole is at the universities of Bournemouth and Southampton, and is a clinical neurophysiologist at Poole Hospital, Longfleet Road, Poole BH15 2JB, UK. 